\title{
Frequency and perceived burden of diabetes self-management activities in employees with insulin-treated diabetes: relationships with health outcomes
}

\author{
Iris Weijman ${ }^{\mathrm{a}}$, Wynand J.G. Ros ${ }^{\mathrm{a}, *}$, Guy E.H.M. Rutten ${ }^{\mathrm{a}}$, Wilmar B. Schaufeli ${ }^{\mathrm{b}}$, \\ Marc J. Schabracq ${ }^{\mathrm{c}}$, Jacques A.M. Winnubst ${ }^{\mathrm{a}}$ \\ ${ }^{a}$ Julius Center for Health Sciences and Primary Care, Section of Medical and Health Psychology, \\ University Medical Center, Str. 3.130, P.O. Box 85060, 3508 AB Utrecht, The Netherlands \\ ${ }^{\mathrm{b}}$ Department of Social and Organizational Psychology, Utrecht University, \\ Utrecht, The Netherlands \\ ${ }^{\mathrm{c}}$ Department of Work and Organizational Psychology, University of Amsterdam, \\ Amsterdam, The Netherlands
}

Received 25 February 2004; received in revised form 4 August 2004; accepted 10 August 2004 Available online 12 October 2004

\begin{abstract}
We explored the relationship between frequency and perceived burden of different self-management activities and $\mathrm{HbA}_{1 \mathrm{c}} \%$, symptoms of diabetes, fatigue, depression, and quality of life in 292 employees between 30 and 60 years of age with insulin-treated diabetes. Participants completed questionnaires that assess self-management and health-related variables. $t$-Tests were performed for type 1 (DM1) and type 2 diabetes (DM2) separately to compare the mean health scores of individuals who frequently or infrequently perform self-management activities and who do or do not perceive this as a burden. Participants frequently perform their self-management activities, particularly injection of insulin (96.1\%), following dietary guidelines $(70.8 \%)$ and eating regularly $(65.6 \%)$. Dietary self-management is most often seen as a burden $(70.4 \%)$, while injecting insulin is seen as least burdensome $(12.8 \%)$. The perceived burden of self-management is more strongly related to health than the frequency of self-management. Frequency of self-management especially relates to $\mathrm{HbA}_{1 \mathrm{c}} \%$ in DM1. People with DM2 who frequently follow the dietary guidelines have more positive health outcomes. Participants who perceive dietary self-management and injecting insulin as a burden have more negative health outcomes. Because different relationships were found between frequency and perceived burden of self-management and health
\end{abstract}

Abbreviations: MDSC, Multidimensional Diabetes Self-Management Checklist; m2, one-year follow-up measure; HbA $\mathrm{Ac}_{1 \mathrm{c}}$, glycated haemoglobin; CIS, Checklist Individual Strength; CES-D, Center for Epidemiologic Studies Depression Scale; MOS-SF20, Medical Outcomes Study Short-Form General Health Survey; DSC-R, Diabetes Symptom Checklist-Revised; DM1, type 1 diabetes mellitus; DM2, type 2 diabetes mellitus; $\mathrm{m} 1$, first measurement

* Corresponding author. Tel.: +31302538882; fax: +31 302539038 .

E-mail address: w.j.g.ros@med.uu.nl (Wynand J.G. Ros). 
indicators, both aspects should be assessed and considered separately when evaluating self-management and examining patient's health.

(C) 2004 Elsevier Ireland Ltd. All rights reserved.

Keywords: Insulin treatment; Diabetes self-management; Fatigue; Quality of life; Diabetes symptoms; $\mathrm{HbA}_{1 \mathrm{c}} \%$

\section{Introduction}

Self-management is an important issue in daily life for people with diabetes $[1,2]$. The main components of a diabetes treatment regimen include selfmonitoring of blood glucose, using medication properly, complying with an appropriate eating plan, engaging in regular exercise, and adjusting medication, food and exercise on the basis of circumstances and blood glucose levels [3]. The aim of blood glucose-lowering treatment is to optimize glycaemic control in order to prevent and minimize long-term diabetes complications [4-6] and to enhance the quality of life [7].

Self-management activities require a great deal of effort [6], may be difficult to incorporate into one's daily life [3], and their results are not always clear immediately [8]. Flexibility in self-management is important, but it may also make large demands on people [9]. Consequently, self-management may be perceived as burdensome, frustrating, and even overwhelming [10], and therefore also affect health negatively $[11,12]$.

The methods for assessing self-management are diverse [6]. Previous studies sometimes calculated a total score for self-management [13,14], but researchers now agree that different aspects of self-management should be assessed separately because of its multidimensional nature [15-17]. A variety of questionnaires have been developed, most of which focus on the frequency with which people perform their selfmanagement tasks in a variety of areas. Another approach to self-management and a way to measure it is to focus on the experienced burden of performing self-management activities. This is in line with stresscoping theories [18,19], which take the appraisal of the situation into account in relation to one's health status and not only the 'objective' situation. The questionnaire in this field that does not exclusively rely on frequencies concerns the perceived difficulties in adherence [20], but adherence is not the same as self-management. Whereas self-management implies that patients are responsible for managing their disease in collaboration with their health professionals, adherence refers to patients behavior in relation to clinical recommendations of health-care providers $[1,21,22]$. However, in our opinion actual self-management behavior should be assessed (the number of occurrences) as well the perceived burden of performing these behaviors.

In this paper, we start with exploring the relationship between frequency and burden of self-management. Next, we report about the relationship between self-management in insulin-treated patients and diabetes regulation and the following health-related variables: diabetes-related symptoms, fatigue, depression, and quality of life. For the different types of selfmanagement activities that were studied, the following aspects were taken into account: the frequency with which people perform self-management activities and the perceived burden of performing this behavior at home, at work, and during social occasions. We hypothesize, based on theories and assumptions regarding self-management [4-6,23], that performing self-management activities frequently is related to positive health outcomes. For the burden of selfmanagement, we hypothesize that a higher experienced burden will be related to poorer health.

\section{Methods}

\subsection{Study population}

We approached employed people with insulintreated diabetes mellitus (types 1 and 2) between 30 and 60 years of age who attended three outpatient diabetes clinics in the Netherlands to participate in the study. This study is part of a larger project on fatigue in the diabetes working population and consequently only employees (who are gainfully part-time or fulltime employed or self-employed) were invited to take 
part [24]. The age range was chosen, because most employees in this category have a stable working position. Internists selected patients in this age range with DM1 and DM2 (diagnosis based upon their own judgement) who injected insulin from their patient's records. From the 626 employees who were approached and met the inclusion criteria, 347 were willing to participate (response rate 55.4\%) and gave their informed consent. At baseline (m1), 317 participants (166 with DM1 and 151 with DM2) completed the set of questionnaires. Data of 25 of them were not analyzed because they were unemployed $(n=10)$, were pregnant $(n=1)$, had not worked for more than 6 weeks due to illness $(n=8)$, did not fill in the questionnaire properly due to different reasons $(n=6)$. The Medical Ethics Committees of the University Medical Center Utrecht approved the study design.

\subsection{Measures}

Participants completed a variety of questionnaires that measured diabetes self-management activities and four health-related variables: (1) diabetes symptoms, (2) fatigue, (3) depressive symptoms and (4) healthrelated quality of life. In addition, data on $\mathrm{HbA}_{1 \mathrm{c}} \%$ were retrieved.

\subsubsection{Diabetes self-management activities}

The Multidimensional Diabetes Self-management Checklist (MDSC) [25] measures four domains of self-management activities for individuals with insulin-treated diabetes: (1) dietary self-management (following dietary guidelines, eating regularly); (2) injecting insulin (the recommended frequency, the recommended dosage of insulin); (3) blood-glucose monitoring; (4) adjusting the insulin dosage to specific circumstances. These four self-management activities have been selected because they may be difficult to plan for and interfere with one's daily routines. The checklist measures the frequency with which people perform self-management activities (one item per activity) as well as the experienced burden of performing the activity at home, at work, and during special occasions (e.g., a party, a day out, vacation). Questions about the frequency ('How often do you ..., e.g., check your blood glucose level?') had six response categories: less than once a month $(0)$; once a month (1); a few times a month (2); once a week (3); a few times a week (4); every day or a few times a day (5). People who reported that they performed selfmanagement behaviors every day were considered as being 'frequent self-managers', whereas people who performed self-management activities a few times a week or less were regarded as infrequent selfmanagers'. Each question about the perceived burden of different self-management activities had four response categories: no, I (almost) never perceive it as a burden (0); sometimes (1); often (2); yes, most of the time I perceive it as a burden (3). These items were recoded into '(almost) never perceived as a burden' (0) and 'sometimes to most of the time perceived as a burden' (1) as follows: when more than half of the items regarding a specific activity had a score of 1 , it was considered that performing the specific activity was perceived as a burden.

\subsubsection{Health-related variables}

$\mathrm{HbA}_{1 \mathrm{c}} \%$ was used as a measure of glycaemic control (HPLC, immunogenic, normal range 4-6\%).

The score on the Diabetes Symptom ChecklistRevised (DSC-R) was used as a measure of symptom severity [26]. A composite score (ranging from 0 to 100) was established on the basis of eight underlying dimensions: hyperglycemic, hypoglycemic, psychosocial-cognitive, psychosocial-fatigue-related, cardiovascular, neurological-pain-related, neurologicalsensory, and ophthalmologic complaints. A coefficient $\alpha$ of 0.83 was found for this scale. Higher scores indicate more reported symptoms.

General fatigue was measured by the Checklist Individual Strength (CIS) [27]. Scores range from 20 to 140 . Higher scores indicate more reported fatigue symptoms. Employees scoring $>76$ were defined as probable cases of prolonged fatigue [28].

The Center for Epidemiologic Studies Depression Scale (CES-D) [29] was used to assess depressive symptomatology. Scores range from 0 to 60 . Higher scores indicate more depressive symptoms in the last week. Participants with scores higher than 16 are considered as possibly deformed [30].

The Medical Outcomes Study Short-Form General Health Survey (MOS-SF20) [31] derived from the full-length MOS Health Survey was used. This questionnaire was designed to assess the impact of chronic disease on quality of life [32]. The SF-20 
Table 1

Study population: characteristics

\begin{tabular}{llll}
\hline & Total (292) & DM1 (159) & DM2 (133) \\
\hline Age (years) & $44.6(8.8)$ & $40.3(7.6)$ & $49.7(8.8)$ \\
Gender (\% men) & 66.8 & 59.0 & 74.6 \\
Disease duration (years) & $16.1(10.7)$ & $21.1(10.7)$ & $10.1(7.2)$ \\
Educational level & & & \\
$\quad$ \% Lower & 35.2 & 26.9 & 45.6 \\
\% Middle & 32.0 & 32.7 & 31.2 \\
\% Higher & 32.7 & 40.4 & 23.2 \\
\hline
\end{tabular}

assesses six dimensions of health status: physical functioning, role functioning, social functioning, mental health, perceived health, and physical pain. Explorative factor analysis showed that all sub-scales loaded on one factor (variance explained by this factor: 53.8\%). Therefore, we used a composite score (ranging from 0 to 100) based on the different subscales (coefficient $\alpha=0.81$ ), which is a global indicator for health-related quality of life. Higher scores indicate better functioning.

\subsection{Statistical analyses}

To analyze the data, we used SPSS version 10.0.5. Differences in scores between participants with DM1 and DM2 were calculated by means of $t$-tests and chisquare tests. $t$-Tests were performed to analyze the relationships between self-management and health variables for people with DM1 and DM2 separately. For the frequency of injecting insulin, $t$-tests could not be applied because of the minimal variance.

\section{Results}

\subsection{Study population}

Table 1 shows the characteristics of the study population. In Table 2, the percentages of participants who frequently perform their self-management activities and who perceive this as a burden are shown. Participants with DM2 inject the prescribed number of insulin injections more frequently than those with DM1 $\left(\chi^{2}=6.54 ; P=0.011\right)$. In contrast, people with DM1 check their blood glucose level $\left(\chi^{2}=13.54 ; P=\right.$ 0.000 ) and adjust their insulin dosages more frequently $\left(\chi^{2}=22.88 ; P=0.000\right)$. With regard to the perceived burden of self-management, no significant differences were found between participants with DM1 and DM2 (Table 2).

Table 3 shows the mean scores of the health-related variables under study. Participants with DM2 reported more diabetes-related symptoms compared to participants with DM1 $(t=3.14 ; P=0.002)$. However, no difference was seen in $\mathrm{HbA}_{1 \mathrm{c}} \%$, the level of fatigue, depressive symptoms, and total quality of life. With regard to the different dimensions of quality of life,

Table 2

Description of the frequency and perceived burden of performing self-management activities

\begin{tabular}{lllll}
\hline & Total (292) & DM1 (159) & DM2 (133) & Difference (DM1 - DM2) \\
\hline Frequency & & & & $\chi^{2}=0.80$ \\
$\quad$ Following dietary guidelines & 70.8 & 73.0 & 68.2 & $\chi^{2}=0.69$ \\
Eating regularly & 65.6 & 63.5 & 68.2 & $\chi^{2}=6.54^{*}$ \\
Injecting insulin & 96.1 & 93.3 & 99.2 & $\chi^{2}=13.54^{* * * *}$ \\
Blood glucose testing & 47.8 & 57.6 & 35.9 & $\chi^{2}=22.88^{* * *}$ \\
Adjusting insulin dosages & 54.3 & 67.1 & 38.9 & $\chi^{2}=3.27$ \\
Burden & & & 75.8 & $\chi^{2}=0.63$ \\
Dietary self-management & 70.4 & 66.0 & 14.5 & $\chi^{2}=0.08$ \\
Injecting insulin & 12.8 & 11.3 & 53.0 & $\chi^{2}=3.21$ \\
Blood glucose testing & 54.0 & 54.7 & 38.3 & \\
Adjusting insulin & 32.8 & 28.3 & & \\
\hline
\end{tabular}

Data are percentages of participants who frequently perform self-management activities and percentages of participants who perceive performing self-management activities as a burden. Differences between DM1 and DM2 were tested. In the last column, chi-squares are shown. ${ }^{*} P<0.05$.

**** $P<0.001$. 
Table 3

Description of health-related variables

\begin{tabular}{|c|c|c|c|c|c|c|}
\hline & Total (292) & DM1 (159) & DM2 (133) & $\begin{array}{l}\text { Difference } \\
\text { (DM1 - DM2) }\end{array}$ & $\begin{array}{l}\text { Reference } \\
\text { group }\end{array}$ & $\begin{array}{l}\text { Difference } \\
\text { (total - } \\
\text { reference group) }\end{array}$ \\
\hline $\mathrm{HbA}_{1 \mathrm{c}} \%$ & $8.20(1.21)$ & $8.12(1.12)$ & $8.30(1.31)$ & $t=-1.16$ & - & - \\
\hline Diabetes symptoms & $18.64(14.07)$ & 16.25 (11.59) & $21.50(16.15)$ & $t=-3.14^{* *}$ & - & - \\
\hline Fatigue & $62.01(26.45)$ & $60.53(26.41)$ & $63.78(26.49)$ & $t=-1.05$ & $41.5(19.8)$ & $t=13.25^{* * *}$ \\
\hline Depressive symptoms & $9.73(8.83)$ & $9.16(8.48)$ & $10.42(9.22)$ & $t=-1.21$ & $8.2(7.2)$ & $t=2.95^{* *}$ \\
\hline $\begin{array}{l}\text { Health-related quality } \\
\text { of life, total score }\end{array}$ & $72.36(19.73)$ & $74.14(18.13)$ & $70.26(21.35)$ & $t=1.65$ & - & - \\
\hline Physical functioning & $78.77(27.36)$ & $83.96(23.56)$ & $72.56(30.23)$ & $t=3.54^{* * *}$ & $67.8(29.6)$ & $t=6.85^{* * *}$ \\
\hline Role fulfillment & $82.29(34.15)$ & $85.48(31.71)$ & $78.57(36.56)$ & $t=1.70$ & $73.7(41.3)$ & $t=4.27^{* * *}$ \\
\hline Social functioning & $83.88(22.77)$ & $84.84(21.53)$ & $82.73(24.18)$ & $t=0.79$ & $80.9(25.7)$ & $t=2.22^{*}$ \\
\hline Mental health & $71.61(18.27)$ & $70.70(17.43)$ & 72.69 (19.24) & $t=-0.92$ & $76.0(18.9)$ & $t=-4.09^{* * *}$ \\
\hline Perceived health & $55.51(26.34)$ & $58.10(25.78)$ & $52.44(26.77)$ & $t=1.83$ & $67.6(24.8)$ & $t=-7.79^{* * *}$ \\
\hline Physical pain & $37.76(32.21)$ & $38.21(32.05)$ & $37.22(32.51)$ & $t=0.26$ & $30.4(31.1)$ & $t=3.90^{* * *}$ \\
\hline
\end{tabular}

Data are means (S.D.). Differences between DM1 and DM2 were tested by $t$-test (fifth column). Also, differences between the total population and reference groups were tested (one sample $t$-tests). These results are shown in the last column.

$$
\begin{aligned}
& { }^{*} P<0.05 . \\
& { }^{* *} \quad P<0.01 . \\
& { }^{* * * *} \quad P<0.001 .
\end{aligned}
$$

participants with DM2 reported worse physical functioning $(t=3.54 ; P=0.000)$. However, analysis of variance shows that in physical functioning there is no difference between DM1 and DM2 when corrected for age. Mean scores and standard deviations from different reference groups are also shown in Table 3. People with diabetes reported more fatigue and more depressive symptoms than healthy individuals. In contrast to individuals in the age category of 57-99 years, people with diabetes reported better physical functioning, better role fulfillment and social functioning, but worse mental health, worse experienced health and more physical pain.

\subsection{Relationship between frequency and burden of performing self-management activities}

We also explored the relationships between the frequency with which participants perform their selfmanagement activities and the perceived burden of doing so. Results are shown in Table 4. For the total population, significant relationships were found

\begin{tabular}{|c|c|c|c|c|c|c|c|c|c|c|c|c|}
\hline & \multicolumn{3}{|c|}{$\begin{array}{l}\text { Burden dietary } \\
\text { self-management }\end{array}$} & \multicolumn{3}{|c|}{ Burden injecting insulin } & \multicolumn{3}{|c|}{$\begin{array}{l}\text { Burden blood glucose } \\
\text { testing }\end{array}$} & \multicolumn{3}{|c|}{$\begin{array}{l}\text { Burden adjusting } \\
\text { insulin }\end{array}$} \\
\hline & Total & DM1 & DM2 & Total & DM1 & DM2 & Total & DM1 & DM2 & Total & DM1 & DM2 \\
\hline \multicolumn{13}{|l|}{ Frequency } \\
\hline Dietary guidelines & $6.38^{*}$ & 3.01 & 3.10 & 0.05 & 2.02 & 2.31 & $4.27^{*}$ & $5.39^{*}$ & 0.34 & 2.22 & $5.34^{*}$ & 0.10 \\
\hline Eating regularly & $15.16^{* * *}$ & $16.56^{* * *}$ & 1.75 & $6.54^{*}$ & 3.79 & 2.99 & 2.37 & 1.99 & 0.50 & 1.21 & 1.72 & 0.12 \\
\hline Injecting insulin & 2.21 & 2.54 & 0.33 & $10.67^{\text {*** }}$ & $8.58^{* *}$ & $5.84^{*}$ & 0.42 & 0.11 & 0.89 & 1.15 & 0.36 & 0.64 \\
\hline Blood glucose testing & 0.44 & 0.14 & 0.76 & 0.60 & 0.06 & 1.21 & $8.01^{* *}$ & 1.77 & $8.78^{* * *}$ & 0.19 & 0.55 & 0.83 \\
\hline Adjusting insulin dosage & 0.15 & 2.67 & 0.21 & 0.40 & 0.98 & 0.08 & 1.85 & 0.84 & 1.37 & $5.50^{*}$ & 0.20 & $5.49^{*}$ \\
\hline
\end{tabular}

Table 4

Relationship between frequency and burden of self-management

Data are presented as $\chi^{2}$ with significance levels.

${ }^{*} P<0.05$.

** $P<0.01$.

${ }^{* * * *} P<0.001$. 
Table 5

Differences between infrequent vs. frequent self-management and low vs. high perceived burden of self-management in relation to $\mathrm{Hb}_{\mathrm{lc}} \%$, diabetic symptoms, fatigue, depression, and health-related quality of life

\begin{tabular}{|c|c|c|c|c|c|c|c|c|c|c|}
\hline & \multicolumn{2}{|l|}{$\mathrm{HbA}_{1 \mathrm{c}} \%$} & \multicolumn{2}{|c|}{$\begin{array}{l}\text { Diabetic } \\
\text { symptoms }\end{array}$} & \multicolumn{2}{|l|}{ Fatigue } & \multicolumn{2}{|c|}{ Depression } & \multicolumn{2}{|c|}{ Quality of Life } \\
\hline & DM1 & DM2 & DM1 & DM2 & DM1 & DM2 & DM1 & DM2 & DM1 & DM2 \\
\hline \multicolumn{11}{|l|}{ Frequency } \\
\hline Dietary guidelines & 1.26 & 1.26 & 0.49 & $-2.35^{*}$ & -1.18 & $-3.22^{* *}$ & -0.37 & $-2.09^{*}$ & -1.55 & $2.35^{*}$ \\
\hline Eating regularly & $2.37^{*}$ & 1.11 & 0.78 & -0.78 & -1.03 & -1.76 & -0.87 & -1.62 & -0.05 & $2.67^{* * *}$ \\
\hline Blood glucose testing & $-2.42^{*}$ & -1.38 & 1.54 & -0.17 & 1.39 & 0.71 & 0.66 & 0.17 & -0.13 & 0.26 \\
\hline Adjusting insulin dosage & $-2.64^{* *}$ & -0.92 & 0.28 & -1.03 & 0.98 & -0.91 & 1.46 & -1.01 & -0.68 & 0.02 \\
\hline \multicolumn{11}{|l|}{ Burden } \\
\hline Dietary self-management & $-2.15^{*}$ & 1.24 & $2.52^{*}$ & $2.39^{*}$ & $2.62^{* *}$ & $2.45^{*}$ & $2.00^{*}$ & 1.38 & -0.69 & -1.69 \\
\hline Injecting insulin & 1.34 & $2.57^{*}$ & $3.57^{* * * *}$ & $3.12^{* *}$ & 1.50 & $3.69^{* * * *}$ & 1.37 & $3.07^{* * *}$ & $-2.70^{* *}$ & $-3.03^{* *}$ \\
\hline Blood glucose testing & 0.58 & 1.87 & 1.29 & 1.22 & 1.61 & 1.33 & $3.38^{* *}$ & 0.78 & -0.56 & -1.71 \\
\hline Adjusting insulin & 0.35 & 1.76 & 0.65 & 1.31 & $2.26^{*}$ & 1.86 & $2.03^{*}$ & 1.73 & -1.45 & -0.72 \\
\hline
\end{tabular}

Data are $t$-values and shown for DM1 and DM2 separately. Positive $t$-values indicate that the mean scores of people who frequently perform selfmanagement are higher than those who infrequently perform self-management activities. Also, positive $t$-values indicate that the mean scores of people who perceive self-management as a burden are higher than those who do not perceive self-management as a burden.

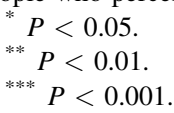

between the frequency of a specific self-management activity and its perceived burden. In addition, significant relationships were also found between frequency of complying with dietary guidelines and perceived burden of blood glucose control and between frequency of eating at regular times and perceived burden of injecting insulin. In DM1, the perceived burden of blood glucose testing and adjusting insulin are not related to the frequency of blood glucose testing and adjusting insulin, but to the frequency with which dietary guidelines were followed. In all cases, participants who do not perceive performing self-management activities as a burden are more likely to perform these activities frequently.

\subsection{Frequency of self-management in relationship to health outcomes}

Participants with DM2 who followed dietary guidelines frequently reported fewer diabetic symptoms, were less fatigued, less depressed and had a higher quality of life. $\mathrm{HbA}_{1 \mathrm{c}} \%$ did not differ from the level of those patients with DM2 who did not follow the dietary guidelines frequently. Also, participants with DM2 who frequently eat at regular times have a better quality of life than those who do not. For participants with $\mathrm{DM} 1, \mathrm{HbA}_{1 \mathrm{c}} \%$ was higher when they reported eating at regular times of day and lower when they frequently tested their blood glucose levels and adjusted their insulin dosages (Table 5).

\subsection{Perceived burden of self-management in relationship to health outcomes}

A high perceived burden of dietary self-management was associated with more diabetic symptoms and more fatigue in participants with DM1 and DM2. In DM1, a high perceived burden of dietary self-management was also related to lower $\mathrm{HbA}_{1 \mathrm{c}} \%$ and more depression. A high perceived burden of injecting insulin was associated with more diabetic symptoms for participants with DM1 as well as DM2 and a worse quality of life. In DM2, a high burden of injecting insulin was also related to higher $\mathrm{HbA}_{1 \mathrm{c}} \%$, more fatigue and more depressive symptoms. No differences in health scores were found for participants with DM2 who do or do not perceive blood-glucose monitoring and insulin adjustment as a burden. In DM1, a high burden of blood glucose monitoring and adjusting insulin was associated with more depression. A high burden of adjusting insulin was also related to more fatigue in DM1 (Table 5). 


\section{Discussion and conclusions}

Most people who inject insulin daily perform selfmanagement activities. As could be expected, almost all participants inject insulin frequently. Many of them also follow dietary guidelines frequently and eat at regular times, as shown in several other studies $[33,34]$. Most people with DM2 do not test their blood glucose levels frequently, nor do they adjust their insulin dosages. They often do not learn how to adjust their insulin dosages, but the majority of participants do not perceive injecting insulin and adjusting insulin as a burden. People with DM1 check their blood glucose levels and adjust their insulin dosages more frequently. Probably for this reason they injected less frequently the prescribed number of insulin injections. These results may explain why they reported less diabetes symptoms and tend to have lower $\mathrm{HbA}_{1 \mathrm{c}}$ levels. Their self-management probably is better. It was also found that participants who do not perceive self-management as a burden perform their self-management activities more frequently. It could have been expected that performing self-management activities on a daily basis is burdensome for patients and that people who perform these activities frequently would therefore be more likely to perceive it as a burden. Although the results of our study do not support this, they are in line with the results of another study [35]. People may perform self-management more often when they find it easier. They tend to make decisions on the basis of current symptoms instead of the long-term benefits of self-management actions [8]. Also, when people feel able to perform self-management activities (self-efficacy), it is possible that they will perform their self-management more frequently $[36,37]$ and at the same time do not perceive it as a burden. Other factors may also be related to both frequency and burden of self-management, such as social support, coping styles, optimism, and a person's energy level. It would be very interesting to untangle the primacy and directions of effect between frequency and perceived burden of selfmanagement.

When we studied relationships between selfmanagement and a diversity of health indicators, it was shown that more relationships were found between the perceived burden of self-management and health than between frequency of self-management and health. There was not much variation in scores with regard to frequency of self-management. This may explain the poor relationships that were found. Substantial relationships between the frequency of self-management activities and glycaemic control were found, but only in persons with DM1 and not always in the expected direction. $\mathrm{HbA}_{1 \mathrm{c}} \%$ was higher when people with DM1 reported frequently eating at regular times. People with poorly controlled diabetes may follow their diabetes treatment more rigidly compared to people with good control [38]. We cannot explain the differences between DM1 and DM2. Probably participants with DM1 cope differently with poor control than participants with DM2.

Following the dietary guidelines daily is, as was hypothesized, related to less diabetic symptoms, less fatigue, less depressive symptoms, and better quality of life for persons with DM2 but not for persons with DM1. This may be so because individuals with DM2 are confronted with the disease at a later stage of their life. Therefore, dietary advice might be seen as a more important aspect and will thus positively influence health when people actually follow dietary guidelines. For the perceived burden of self-management, all relationships found were in the expected direction: the perceived burden of self-management is related to a less favorable health status.

Due to the cross-sectional design, this study does not allow us to draw causal conclusions. The results might suggest that self-management affects one's health status, but it also may be possible that for people who feel tired, or have depressive symptoms it may be more difficult to perform self-management activities frequently. They also may have more negative self-evaluation in most self-management areas. It will therefore be more burdensome for them to perform self-management activities. Diabetesrelated symptoms may have a different relationship with the other variables under study compared to the above-mentioned health indicators. Due to better health status it may be easier to perform selfmanagement activities, which may result in less diabetes symptoms. In addition to the inability to draw causal conclusions, the results of this study may be limited due to the relatively high non-response, although the response rate is comparable to those 
found in other studies on related topics [39,40]. Therefore, we assume that generalizability of results will not be more problematic here than in other studies. Generalizability of results may, however, be limited because people with tablet-treated diabetes and those who were unemployed were not included in this study. We suggest that future research should focus on the relationships between frequency as well as the burden of self-management and different health outcomes in different diabetes subpopulations.

\subsection{Practical implications}

We conclude that health-care providers should not just stress the importance of performing self-management tasks. In addition to asking patients about the frequency of performing self-management tasks, health-care providers should also ask patients how demanding self-management activities are. When it turns out that they perceive certain activities as a burden, more information about the specific situation and the reasons for their perception could guide the counseling and thus lead to an improvement of psychological health, quality of life, and diabetic symptoms. Furthermore, physicians should be aware that patients with depressive symptoms, or with other (psychological) health complaints, may be more likely to perceive aspects of their self-management as a burden. Because frequency and burden of selfmanagement relate to health outcomes differently, it can also be concluded that self-management measures should include items on the perceived burden of performing activities. The focus should not be primarily on the number of occurrences. In this respect we agree with other authors, who also advocate the assessment of the impact of diabetes, such as the interference of diabetes on daily life [41], and the emotional adjustment to life with diabetes [42].

\section{Acknowledgements}

This work was supported by grants of Utrecht University and the Priority program 'Fatigue at work' of the Netherlands Organization for Scientific Research (NWO).

\section{References}

[1] R.E. Glasgow, R.M. Anderson, In diabetes care, moving from compliance to adherence is not enough, Diabetes Care 22 (12) (1999) 2090-2092.

[2] J. Barlow, C. Wright, J. Sheasby, A. Turner, J. Hainsworth, Self-management approaches for people with chronic conditions: a review, Patient Educ. Couns. 48 (2002) 177-187.

[3] R.E. Glasgow, E.G. Eakin, Issues in diabetes self-management, in: S.A. Shumaker, E.B. Schron, J.K. Ockene, W.L. McBee (Eds.), The Handbook of Health Behavior Change, Springer, New York, 1998, pp. 435-461.

[4] American Diabetes Association, Third-party reimbursement for diabetes care, self-management education, and supplies, Diabetes Care 26 (1) (2003) S143-S144.

[5] P.S. Ciechanowski, W.J. Katon, J.E. Russo, E.A. Walker, The patient-provider relationship: attachment theory and adherence to treatment in diabetes, Am. J. Psychiatry 158 (1) (2001) 2935.

[6] E. Vermeire, J. Wens, P. van Royen, H. Hearnshaw, Interventions for improving adherence to treatment recommendations in people with type 2 diabetes mellitus (Protocol for a Cochrane Review), in: The Cochrane Library Issue 4, Update Software, Oxford, 2002.

[7] H.M.J. Krans, M. Porta, H. Keen (Eds.), Diabetes Care and Research in Europe: The St. Vincent Declaration Action Programme, World Health Organization, Regional Office for Europe, Copenhagen, 1992.

[8] A.M. Jacobson, M. de Groot, J. Samson, Quality of life research in patients with diabetes mellitus, in: J.E. Dimsdale, A. Baum (Eds.), Quality of Life in Behavioral Medicine Research, Lawrence Erlbaum Associates, Hillsdale, NJ, 1995, pp. 241-262.

[9] M. Watson, E. Briganti, T. Skinner, C. Manning, Self-management strategies for adults with type 1 diabetes mellitus (Protocol for a Cochrane Review), in: The Cochrane Library Issue 1, Update Software, Oxford, 2003.

[10] W.H. Polonsky, Understanding and assessing diabetes-specific quality of life, Diabetes Spectrum 13 (2000) 36-41.

[11] K.W. Watkins, C.M. Connell, J.T. Fitzgerald, L. Klem, T. Hickey, B. Ingersoll-Dayton, Effect of adults' self-regulation of diabetes on quality-of-life outcomes, Diabetes Care 23 (10) (2000) 1511-1515.

[12] J.F. Miller, Energy deficits in chronically ill persons with arthritis: fatigue, in: J.F. Miller (Ed.), Coping with Chronic Illness, Davis, Philadelphia, PA, 1992, pp. 196-221.

[13] M. Brownlee-Duffeck, L. Peterson, J.F. Simonds, D. Goldstein, C. Kilo, S. Hoette, The role of health beliefs in the regimen adherence and metabolic control of adolescents and adults with diabetes mellitus, J. Consult. Clin. Psychol. 55 (1987) 139-144.

[14] K.A. Cerkoney, L.K. Hart, The relationship between the health belief model and compliance of persons with diabetes mellitus, Diabetes Care 3 (1980) 594-598.

[15] D.J. Toobert, R.E. Glasgow, Assessing diabetes self-management: the summary of diabetes self-care activities questionnaire, in: C. Bradley (Ed.), Handbook of Psychology and 
Diabetes, Harwood Academic Publishers, Switzerland, 1994, pp. 351-375.

[16] D.J. Toobert, S.E. Hampson, R.E. Glasgow, The summary of diabetes self-care activities measure: results from 7 studies and a revised scale, Diabetes Care 23 (7) (2000) 943-950.

[17] C.M. Orme, Y.M. Binik, Consistency of adherence across regimen demands, Health Psychol. 8 (1989) 27-43.

[18] D.T.D. de Ridder, K. Schreurs, Coping, social support and chronic disease: a research agenda, Psychol. Health Med. 1 (1) (1996) 71-82.

[19] R.S. Lazarus, S. Folkman, Stress, Appraisal, and Coping, Springer, New York, 1984.

[20] B.R. Hanestad, G. Albrektsen, Quality of life, perceived difficulties in adherence to a diabetes regimen, and blood glucose control, Diabetic Med. 8 (1991) 759-764.

[21] K.E. Lutfey, W.J. Wishner, Beyond "compliance" is "adherence": improving the prospect of diabetes care, Diabetes Care 22 (4) (1999) 635-639.

[22] C.S. Rand, K. Weeks, Measuring adherence with medication regimens in clinical care, research, in: S.A. Shumaker, E.B. Schron, J.K. Ockene, W.L. McBee (Eds.), The Handbook of Health Behavior Change, Springer, New York, 1998, pp. 114 132.

[23] M.A. Harris, T. Wysocki, M. Sadler, et al. Validation of a structured interview for the assessment of diabetes self-management, Diabetes Care 23 (9) (2000) 1301-1304.

[24] I. Weijman, W.J.G. Ros, G.E.H.M. Rutten, W.B. Schaufeli, M.J. Schabracq, J.A.M. Winnubst, Fatigue in employees with diabetes: its relationship with work characteristics and diabetes-related burden, Occup. Environ. Med. 60 (1) (2003) i93i98.

[25] I. Weijman, W.J.G. Ros, G.E.H.M. Rutten, W.B. Schaufeli, M.J. Schabracq, J.A.M. Winnubst, The Multidimensional Diabetes Self-management Checklist (MDSC) (internal report), University Medical Center Utrecht, Utrecht, 2003.

[26] P.A. Grootenhuis, F.J. Snoek, R.J. Heine, L.M. Bouter, Development of a type 2 diabetes symptom checklist: a measure of symptom severity, Diabetic Med. 11 (1993) 253-261.

[27] J.H.M.M. Vercoulen, M.M. Alberts, G. Bleijenberg, Kort instrumenteel: de Checklist Individual Strength (CIS) [The Checklist Individual Strength (CIS)], Gedragstherapie 32 (2) (1999) 131-136.

[28] U. Bültmann, M. de Vries, A.J.H.M. Beurskens, G. Bleijenberg, J.H.M.M. Vercoulen, I. Kant, Measurement of prolonged fatigue in the working population: determination of a cutoff point for the Checklist Individual Strength, J. Occup. Health Psychol. 5 (4) (2000) 411-416.

[29] J. Bouma, A.V. Ranchor, R. Sanderman, E. van Sonderen, Het meten van symptomen van depressie met de CES-D: een handleiding [Measurement of depressive symptomatology with the CES-D: a manual], 1995.

[30] W.M. Ensel, Measuring depression: the CES-D scale, in: N. Lin, A. Dean, W.M. Ensel (Eds.), Social Support Life Events and Depression, Academic Press, Orlando, FL, 1986, pp. 5170.

[31] G.I.J.M. Kempen, E.I. Brilman, J.W. Heyink, J. Ormel, Het meten van de algemene gezondheidstoestand met de MOS Short-Form General Health Survey (SF-20): een handleiding [Measurement of the general health status with the MOS Short-Form General Health Status (SF-20): a manual], 1995

[32] J.E.J. Ware, C.D. Sherbourne, The MOS 36-item short-form health survey (SF-36): I. Conceptual framework and item selection, Med. Care 30 (1992) 473-483.

[33] L.J.M. Pennings-van der Eerden, Self-care Behaviour in the Treatment of Diabetes Mellitus: Theory, Assessment and Determinants of Self-care Behaviour and Diabetes Education, Thesis Publishers, Amsterdam, 1992.

[34] M. Toljamo, M. Hentinen, Adherence to self-care and glycaemic control among people with insulin-dependent diabetes mellitus, J. Adv. Nurs. 34 (6) (2001) 780-786.

[35] M. Toljamo, M. Hentinen, Adherence to self-care and social support, J. Clin. Nurs. 10 (5) (2001) 618-627.

[36] J. van der Bijl, A. van Poelgeest-Eeltink, L. Shortridge-Baggett, The psychometric properties of the diabetes management self-efficacy scale for patients with type-2 diabetes mellitus, J. Adv. Nurs. 30 (2) (1999) 352-359.

[37] R.E. Glasgow, D.J. Toobert, C.D. Gillette, Psychosocial barriers to diabetes self-management and quality of life, Diabetes Spectrum 14 (1) (2001) 33-41.

[38] M. Nomura, K. Fujimoto, A. Higashino, et al. Stress and coping behavior in patients with diabetes mellitus, Acta Diabetol. 37 (2) (2000) 61-64.

[39] U. Bültmann, I.J. Kant, S.V. Kasl, A.J.H.M. Beurskens, P.A. van den Brandt, Fatigue and psychological distress in the working population: psychometrics, prevalence, and correlates, J. Psychosom. Res. 52 (6) (2002) 445-452.

[40] F.J. Snoek, R.J. Mollema, R.J. Heine, L.M. Bouter, H.M. van der Ploeg, Development and validation of the Diabetes Fear of Injecting and Self-testing Questionnaire (D-FISQ): first findings, Diabetic Med. 14 (1997) 871-876.

[41] G.M. Devins, R. Dion, L.G. Peletier, et al. Structure of lifestyle disruptions in chronic disease: a confirmatory factor analysis of the illness intrusiveness rating scale, Med. Care 39 (10) (2001) 1097-1104.

[42] G.W. Welch, A.M. Jacobson, W.H. Polonsky, The problem areas in diabetes scale, Diabetes Care 20 (5) (1997) 760766. 